\title{
THE EFFECT OF OXALATE AND CITRATE ON THE PLATELET COUNT OF WHOLE BLOOD AND PLASMA
}

\author{
BY \\ P. BARKHAN \\ From the Department of Medicine, University of Cambridge
}

(RECEIVED FOR PUBLICATION MARCH 8, 1956)

\begin{abstract}
Work on the thromboplastic activity of human platelets necessitated the preparation of platelet concentrates. As a preliminary step, platelet-rich plasma was obtained by slow centrifugation of oxalated or citrated whole blood. Subsequently, it was observed that the supernatant plasma of citrated blood appeared more opalescent and yielded a larger platelet mass than did that derived from oxalate blood. Although citrate and oxalate are commonly used in collecting blood for coagulation studies, no information on such a difference was found in the available literature. More precise quantitative work was necessary to confirm this finding.

The investigation described in this communication was performed to decide whether citrate was superior to oxalate for the purpose of separating the maximal numbers of platelets from blood collected into these two anticoagulants.
\end{abstract}

\section{Materials and Methods}

Collection of the Blood.-Venous blood was collected from the antecubital veins of clinically healthy adult volunteers of both sexes, using $20 \mathrm{ml}$. paraffined glass syringes and size 18 needles. A clean, rapid venipuncture was usually performed, but when difficulty was encountered the aspirated blood was discarded. Nine millilitres of blood from the syringe was immediately transferred to two siliconed conical graduated centrifuge tubes, one containing $1 \mathrm{ml}$. of sodium citrate and the other $1 \mathrm{ml}$. of potassium oxalate. Each tube was then gently inverted thre? times.

Potassium Oxalate. $-\left((\mathrm{COOK})_{2} \cdot \mathrm{H}_{2} \mathrm{O}\right) 0.1 \mathrm{M}(1.84 \%)$.

Sodium Citrate. $-\left(\mathrm{Na}_{3} \mathrm{C}_{6} \mathrm{H}_{5} \mathrm{O}_{i} .2 \mathrm{H}_{2} \mathrm{O}\right) 0.13 \mathrm{M}\left(3.8_{\%}^{\circ}\right)$.

These concentrations of anticoagulant are generally recommended for coagulation studies (Holburn, 1955). The activities of the plasmas from both the citrated and the oxalated blood were found to be almost identical in the one-stage prothrombin and thromboplastin generation tests.

Platelet Counts.-These were done by a direct method, using standard red cell pipettes and a blood dilution of $1: 200$. The total number of platelets in
2 sq. $\mathrm{mm}$. (the central sq. $\mathrm{mm}$. in each chamber) was enumerated in a Spencer "bright-line" haemocytometer. The filled haemocytometer was placed under a moistened Petri dish for 15 minutes before doing the count to allow the platelets to settle. Excellent reproducibility of results with this method of counting was found. Duplicate counts differed by less than 10 . from the mean. The whole blood counts were done within half an hour of collecting the blood and immediately after inverting the tubes three times (using siliconized watch glasses as stoppers). Plasma counts were done immediately after centrifugat:on.

Platelet Counting Fluid.-This had the following composition :

$\begin{array}{lllll}\text { Sequestrene } & \ldots & \ldots & \ldots & 1 \mathrm{~g} . \\ \text { Normal saline } & \ldots & \ldots & \ldots & 100 \mathrm{ml} . \\ \text { Brilliant cresyl } & \text { blue } & \ldots & \ldots & \text { A few crystals }\end{array}$

Platelet-rich Plasma.-Immediately after setting up the whole blood platelet counts the tubes were centrifuged in a horizontal M.S.E. centrifuge at 1.000 r.p.m. for 10 minutes. The oxalated supernatant plasma was usually less opalescent than that of the citrated samples.

Buffy Coat Smears.-With a Pasteur pipette, a small amount of the buffy coat from each centrifuged sample was removed. The buffy coat was usually more prominent in the oxalated samples. Smears were made from this material, dried, and stained with Leishman's stain.

All the work was done at room temperature.

\section{Results}

Fifteen blood samples obtained from different persons were examined. The results are shown in Table I. It is clear that the whole blood counts of the oxalated and citrated samples do not differ significantly.

In striking contrast, the plasma counts show a relatively wide difference. All the citrated samples had a higher platelet concentration. In most instances, the oxalated plasma counts were lower than those of the corresponding whole blood, whereas all the citrated plasma counts were greater than those of the corresponding whole 
TABLE I

DIRECT PLATELET COUNTS ON 15 DIFFERENT SAMPLES OF NORMAL WHOLE BLOOD AND PLASMA USING POTASSIUM OXALATE AND SODIUM CITRATE AS ANTICOAGULANTS

\begin{tabular}{|c|c|c|c|c|}
\hline \multirow{3}{*}{$\begin{array}{c}\text { Sample } \\
\text { No. }\end{array}$} & \multicolumn{4}{|c|}{ Platelets per c.mm. } \\
\hline & \multicolumn{2}{|c|}{ Whole Blood } & \multicolumn{2}{|c|}{ Plasma } \\
\hline & Oxalate & Citrate & Oxalate & Citrate \\
\hline $\begin{array}{r}1 \\
2 \\
3 \\
4 \\
5 \\
6 \\
7 \\
8 \\
9 \\
10 \\
11 \\
12 \\
13 \\
14 \\
15\end{array}$ & $\begin{array}{l}294,800 \\
237,600 \\
290,400 \\
254,100 \\
240,900 \\
160,600 \\
264,000 \\
299,200 \\
251,900 \\
244,200 \\
224,400 \\
227,000 \\
242,000 \\
272,000 \\
272,000\end{array}$ & $\begin{array}{l}282,700 \\
226,600 \\
319,000 \\
254,100 \\
266,200 \\
181,500 \\
290,400 \\
295,900 \\
220,000 \\
214,500 \\
221,100 \\
226,000 \\
215,000 \\
248,000 \\
300,000\end{array}$ & $\begin{array}{r}59,400 \\
363,000 \\
251,900 \\
106,700 \\
178,200 \\
101,200 \\
173,800 \\
214,500 \\
404,800 \\
350,900 \\
229,900 \\
268,000 \\
102,000 \\
91,300 \\
182,000\end{array}$ & $\begin{array}{l}764,500 \\
605,000 \\
647,900 \\
541,200 \\
520,300 \\
257,400 \\
743,600 \\
583,000 \\
578,600 \\
583,000 \\
495,000 \\
735,000 \\
581,000 \\
580,800 \\
662,000\end{array}$ \\
\hline Mean & 251,700 & 250,700 & 204,500 & 591,900 \\
\hline
\end{tabular}

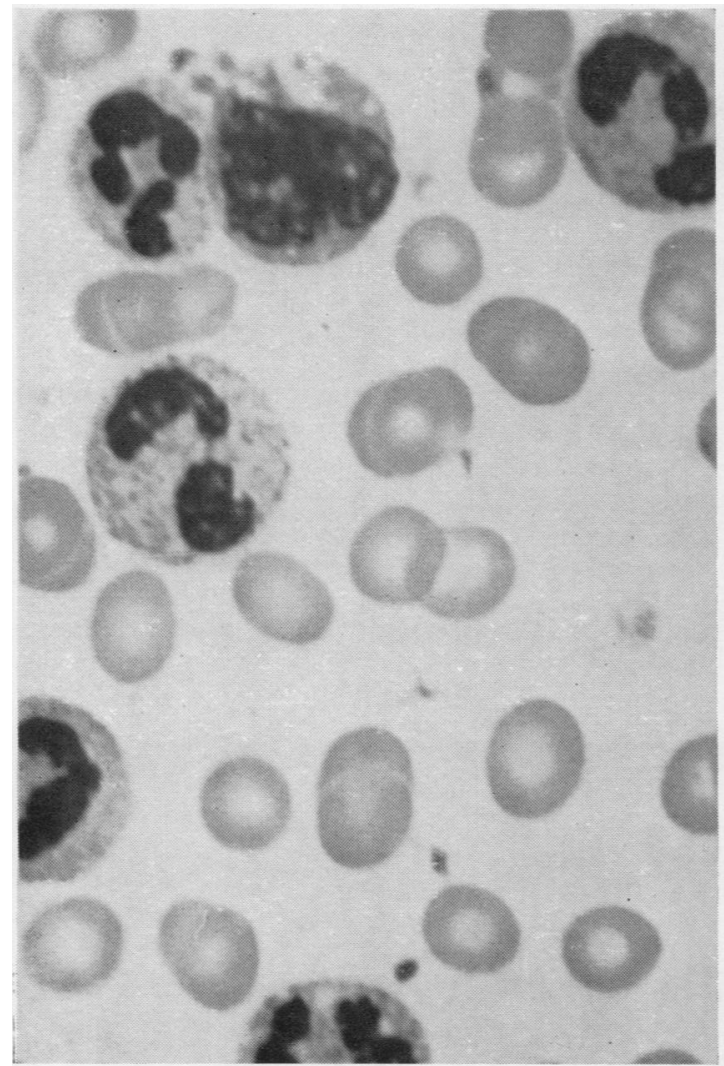

(a)

FIG. 1.-Buffy coat smears from the oxalated and citrated samples of the same blood showing the difference in platelet concentration ( $\times$ 900). (a) Citrated. (b) Oxalated. blood. The mean value of the citrated plasma counts was almost three times greater than that of the oxalated plasma. The plasmas with the lowest platelet counts appeared relatively translucent.

Suspecting that the reduced counts in the oxalated plasma might be the result of their reduced suspension stability during centrifugation, the buffy coats of the two samples were examined. This demonstrated that the oxalated buffy coat contained large numbers of platelets compared with the relatively few in the citrated buffy coat (Fig. 1).

\section{Discussion}

A precise quantitative investigation therefore demonstrated that the plasma from oxalated blood had a lower platelet concentration than that of the same blood collected into citrate, although the whole blood concentrations in the two samples were almost identical.

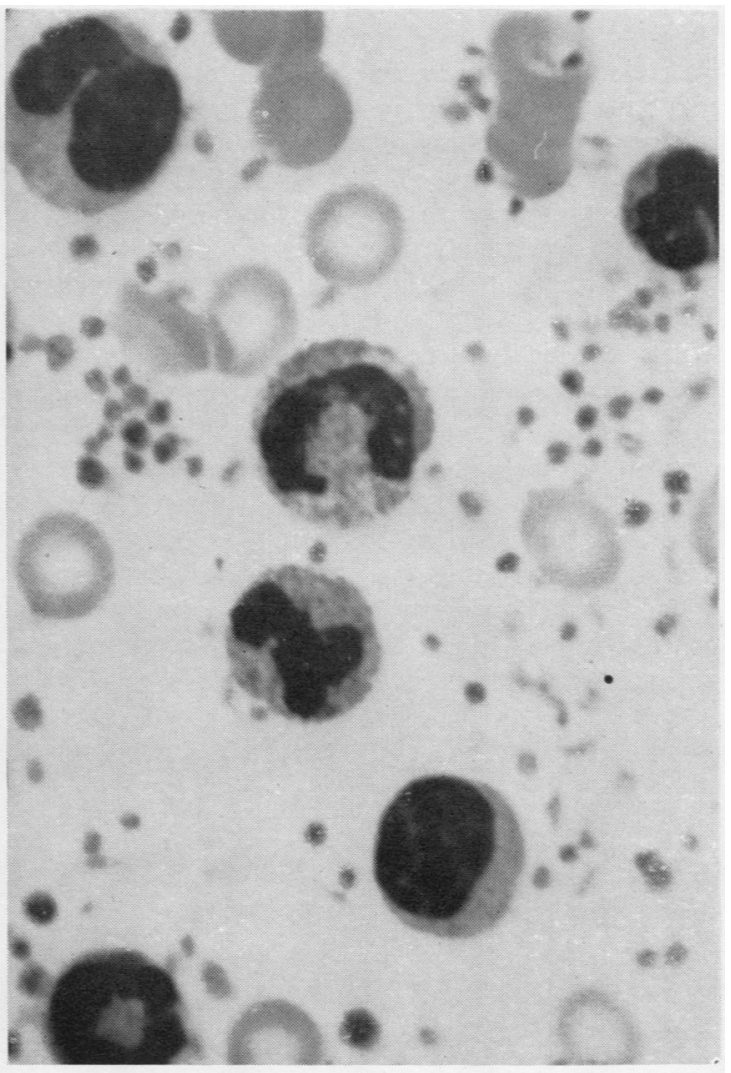

(b) 
The presence of large numbers of platelets in the buffy coat of the oxalated blood compared with the relatively few platelets in that from the citrated blood strongly suggests that the suspension stability on centrifugation of the oxalated platelets is reduced, or conversely that the citrated platelets have a greater suspension stability under these conditions. The reason for this difference is not immediately apparent. The answer may well be found in the difference in their action as anticoagulants. Both exert their action by combining with the calcium in the blood, the oxalate by a direct precipitation, thus removing the calcium completely from solution, and the citrate by forming a complex with the calcium, which, however, remains in solution. This precipitating effect of oxalate on calcium can be easily demonstrated with pure solutions, when a definite cloudiness can be seen after the addition of oxalate to a calcium solution. But no visible change can be observed when the citrate is added in equivalent amount to the solution of calcium. There is evidence (Cohn, 1953 ; Odell and Upton, 1955) that some calcium is adsorbed on to the platelets. A possible explanation of the oxalate effect may be, therefore, that it forms a plateletcalcium-oxalate complex, as a result of which the suspension stability of the platelet is decreased, this becoming manifest when the blood is slowly centrifuged. Since citrate does not precipitate the calcium, it might be expected, by the same reasoning, that the platelet suspension stability in citrate would not be reduced.

Factor $\mathrm{V}$ declines in oxalated but not in citrated stored plasma (Quick and Stefanini, 1948). The possibility arises that this difference between the anticoagulants might also be related to their different actions on calcium. Complete removal of calcium by oxalate might disrupt a factor V-calcium complex. Maintenance of the complex might be necessary for the activity and stability of factor $V$. The experimental find- ings of Stefanini (1950) support the possibility of the existence of such a complex.

\section{Summary}

Quantitative observations have been made on the platelet content of normal whole blood and plasma using solutions of potassium oxalate and sodium citrate as anticoagulants.

In the 15 specimens of normal blood studied, the mean platelet count in the whole blood was 251,700 per c.mm. and 250,700 per c.mm. in the oxalated and citrated samples respectively. The mean platelet count on the corresponding plasma obtained by slow centrifugation of the whole blood was 204,500 per c.mm. and 591,900 per c.mm. in the oxalated and citrated samples respectively.

Oxalated blood buffy coat contained larger numbers of platelets than that from the citrated sample of the same blood.

For separating maximum numbers of platelets from blood by centrifugation, citrate was found to be a better anticoagulant than oxalate.

The lower concentration of platelets found in the oxalated plasma is thought to be related to the decreased suspension stability of the platelets resulting from combination of the oxalate with their adsorbed calcium.

I am indebted to the late Sir Lionel Whitby, Regius Professor of Physic, University of Cambridge, and Dr. F. G. J. Hayhoe for advice in the preparation of this paper. My thanks are due to Miss Sheila Tomlin for valuable technical assistance and to Mr. Roger Flemans for the preparation of the photographs. The work was done during the tenure of an Elmore Research Studentship of the University of Cambridge.

\section{REFERENCES}

Cohn, E. J. (1953). In Blood Cells and Plasma Proteins. Their State in Nature, p. 46, ed. Tullis, J. L. Academic Press, New York.

Holburn, R. R. (1955). In The Coagulation of Blood. Methods of Study, p. 10, ed. Tocantins, L. M. Grune and Stratton, New York and London.

Odell, T. T., Jr., and Upton, A.C.(1955). Acta haemat. (Basel), $14,291$. Quick, A. J., and Stefanini, M. (1948). J. Lab. clin. Med., 33, 819.

Stefanini, M. (1950). Acta med. scand., 136, 250. 